\title{
PERANCANGAN BOARD GAME SEBAGAI MEDIA PENANAMAN MORAL BAGI ANAK USIA 6-9 TAHUN MELALUI PENDEKATAN PENDIDIKAN AGAMA KRISTEN
}

\author{
Angga Hendrawan ${ }^{1}$ \\ Christyan Budi Susilo ${ }^{1}$ \\ Cherly Barbara ${ }^{1}$ \\ Institut Informatika Indonesia, Surabaya ${ }^{l}$ \\ angga@ikado.ac.id
}

\begin{abstract}
Abstrak
Dengan adanya moral, manusia dapat menjalankan fungsi sebagai makhluk sosial dan ekonomi. Kemudian dilakukan sebuah penelitian untuk mendapatkan solusi dengan cara mengumpulkan data primer dan sekunder. Penulis merancang board game untuk menanamkan moral anak melalui pendekatan agama Kristen dengan topik khusus (toleransi dan kepedulian sosial) dengan genre christian's children board game, khususnya untuk anak usia 6-9 tahun, memberi pengalaman perjalanan pelayanan Yesus melalui tantangan dan aktivitas rohani. Board game The Sheepo Adventure ini telah diuji coba dan memberikan dampak yang baik bagi anak. Board game The Sheepo Adventure dikembangkan menjadi kategori moral yang lain, sehingga anak-anak dapat bermain dan belajar mengenai topik moral lainnya.
\end{abstract}

Kata kunci: Papan Permainan, Moral, Kepedulian Sosial

\begin{abstract}
With the existence of morality, man can function as a social and economic being. Then do a research to get solution by collecting primary and secondary data. The author designed the game board to instill moral morality through Christianity's approach to specific topics (tolerance and social awareness) with the christian's children board game genre, especially for children aged 6-9, giving the experience of Jesus' ministry through spiritual challenges and activities. The Sheepo Adventure board game has been tested and has a good impact on the child. The Sheepo Adventure board game is developed into another moral category, so children can play and learn about other.
\end{abstract}

Keywords: Board game, Moralit, Social Awareness 


\section{PENDAHULUAN}

Sebagai makhluk sosial, manusia tidak dapat mengabaikan orang lain. Sebagai makhluk ekonomi, manusia memiliki kecenderungan untuk mementingkan diri sendiri. Meskipun demikian, kedua peran tersebut dapat berjalan seimbang jika manusia menjalankannya dengan nilai-nilai moral. Hasil rekapitulasi focus group discussion dan berdasarkan hasil wawancara dengan Yuliana Gautama selaku konsultan anak menyatakan bahwa banyak kasus perbuatan amoral yang dilakukan oleh anak-anak di sekolah dan gereja, seperti kurang menghormati guru sebagai pengajar, berkelahi dengan teman, bertindak tidak jujur, mengambil barang milik orang lain, berkata-kata kotor, dan lainnya. Menurut hasil pengumpulan data yang telah penulis lakukan menyatakan bahwa moralitas yang dirasa perlu ditangani di Indonesia yaitu mengenai toleransi dan kepedulian sosial. Hal yang dapat menyebabkan penurunan moral anak disebabkan karena pola asuh orang tua yang kurang baik, pengaruh teman sebaya yang tidak terkontrol, perkembangan informasi dan teknologi yang digunakan dengan kurang bijaksana serta pudarnya keimanan, sehingga anak kurang dapat mengontrol emosi (Wijanarko, 2017).

Dari permasalahan umum yang telah disampaikan, maka diperlukan media penanaman moral yang sesuai untuk anak. Penulis telah melakukan riset dengan menyebarkan kuesioner dan wawancara dengan narasumber untuk mendapatkan data yang relevan dan juga mendapat informasi yang valid terhadap permasalahan moral pada anak usia 6 hingga 9 tahun di Surabaya dan didapatkan inti permasalahan sebagai berikut: 1) Berdasarkan hasil wawancara serta focus group discussion menyatakan bahwa permainan sangat penting bagi anak; 2) Berdasarkan hasil kuesioner dan hasil wawancara dengan pendeta serta hasil focus group discussion menyatakan bahwa anak-anak menyukai permainan board game; 3) Berdasarkan hasil kuesioner dan wawancara menyatakan bahwa pendidikan moral melalui sudut pandang agama Kristen dengan media permainan board game itu penting.

Dari hasil riset yang telah dilakukan menunjukkan bahwa kurangnya media yang dapat mendukung penanaman moral dan karakter pada anak di sekolah dan gereja, minimnya permainan dengan pesan moral dengan game play yang menarik dan kurang menariknya tampilan board game yang ada. Oleh karena itu, sangat 
diperlukan perancangan media permainan yang sesuai untuk anak sebagai media penanaman moral serta melibatkan interaksi sosial pada anak, salah satunya adalah board game.

\section{KAJIAN TEORI}

\section{Teori Permainan dan Manfaatnya}

Bermain merupakan kegiatan yang dilakukan secara berulang-ulang untuk mendapatkan kesenangan atau mencapai prestasi tertentu yang diinginkan (Tedjasaputra, 2001). Menurut Hans Daeng (dalam Andang Ismail, 2009:17) permainan adalah bagian mutlak dari kehidupan anak dan permainan merupakan bagian integral dari proses pembentukan kepribadian anak. Bermain menurut Mulyadi (2004), secara umum sering dikaitkan dengan kegiatan anak-anak yang dilakukan secara spontan. Pentingnya permainan bagi perkembangan seseorang, tidak akan terlepas dari manfaat game itu sendiri, baik secara pribadi maupun bagi orang lain. Permainan memiliki banyak manfaat bagi anak, antara lain adalah sebagai berikut: 1) Melatih kemampuan motorik; 2) Melatih konsentrasi; 3) Kemampuan bersosialisasi dan berkompetisi meningkat; 4) Melatih keterampilan bahasa; 5) Menambah wawasan; 6) Mengembangkan kemampuan untuk problem solving: 7) Mengembangkan pengetahuan tentang norma dan nilai; 8) Meningkatkan rasa percaya diri.

\section{Teori Board Game dan Manfaatnya}

Tabletop menurut kamus Oxford adalah "The Horizontal top part of table" atau bagian permukaan dari sebuah meja. Jika ditambah "game" yang secara universal diartikan sebagai permainan, maka Tabletop Game adalah istilah yang lebih umum untuk menyebutkan permainan yang masuk ke dalam kategori board game, card game, pencil and paper game, miniature game dan role playing game. Board game adalah permainan yang dimainkan oleh dua orang atau lebih, berupa papan permainan yang telah di desain sedemikian rupa jenisnya dan di dalamnya terdapat peraturan cara bermain yang dilengkapi dengan beberapa komponen seperti token, pion, atau bidak dan komponen lainnya. 
Berdasarkan wawancara penulis dengan Bapak Adhicipta R Wirawan selaku desainer Board Game Waroong Wars mengatakan bahwa board game memiliki manfaat bagi para pemain sebagai media yang dapat mendekatkan hubungan anak dengan anak, orang tua dengan anak, guru dengan anak, dapat melibatkan kerja sama antar anak, sebagai media edukasi yang menarik bagi anak, dapat menjadi media jenjang generasi yang dapat menjadi jembatan antara orangtua dan anak. Manfaat lainnya adalah sebagai media yang dapat melatih keberanian anak dalam mengambil keputusan dan mau menerima resiko atas keputusan yang diambil.

\section{METODE PENELITIAN}

Dalam wawancara penulis dengan Bapak Adhicipta R Wirawan mengatakan bahwa di dalam pembuatan board game diawali dengan langkah-langkah antara lain: 1) Mendesain permainan yang dimulai dengan a) Menulis ide; b) Menentukan rentang usia pemain; c) Menentukan tujuan; d) Menentukan bagaimana cara pemain akan menang; e) Menulis peraturan dasar. 2) Melakukan tes permainan dengan cara a) Membuat permainan tes; b) Sketsa draf kasar dari desain papan dengan memperhatikan elemen jalur, area bermain, posisi untuk mendarat dan kartu bermain; c) Tes prototype; d) Memainkan dengan teman dan keluarga; e) Tes dengan orang yang berbeda; f) Perbaiki permainan board game. 3) Membuat produk board game final dengan cara a) Mengumpulkan material; b) Merancang ilustrasi papan board game; c) Membuat lempengan permainan; d) Membuat material tambahan.

\section{HASIL DAN PEMBAHASAN}

\section{Proses Perancangan dan Desain Final Media Utama}

Konsep percangan board game ini didapat dari keyword. Keyword didapat dari hasil fenomena, inti masalah, positioning, digabung dengan target audience. Sehingga keyword yang sesuai adalah kindness life. Dalam perancangan ini penulis menentukan tujuan yaitu agar pemain dapat merasakan pengalaman berpetualang dan belajar merasakan perjalanan pelayanan Yesus dan meniru perbuatan-Nya yang suka menolong dan toleransi dengan sesama. Penulis menentukan board game ini untuk anak usia 6-9 tahun dengan konsep permainan yang sederhana dan 
mudah dimengerti. Melakukan riset dengan memainkan banyak board game pada komunitas-komunitas yang ada. Selain itu, penulis juga menentukan bagaimana cara pemain menjadi pemenang yaitu dengan mengumpulkan koin yang paling banyak, pada akhir permainan dapat dilakukan barter sehingga menunjukkan sikap toleransi terhadap sesama.

Menulis peraturan secara terperinci dan membuatnya ke dalam buku panduan dan buku pengetahuan agar memudahkan pemain. Kemudian barulah penulis menyebarkan kuesioner desain dan memulai membuat ilustrasi karakter, logo, media utama hingga media pendukung. Tahapan proses desain dimulai dari membuat sketsa, proses digital hingga desain akhir.

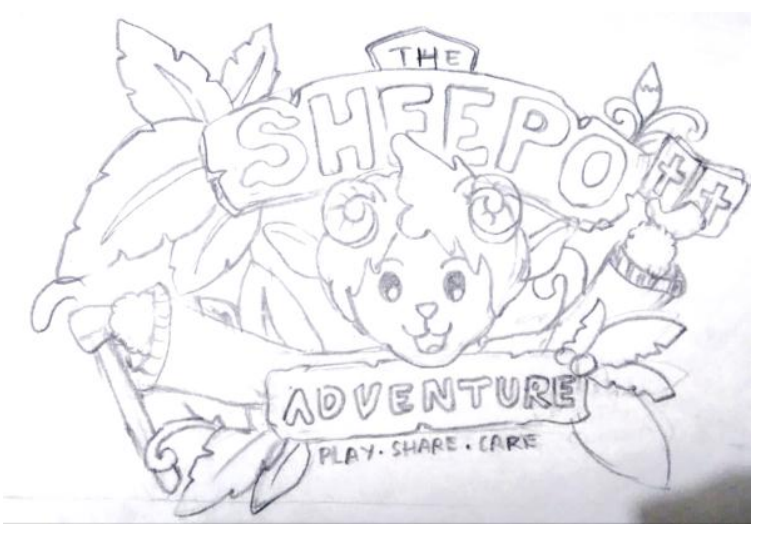

Gambar 1. Sketsa Logo The Sheepo Adventure

Sumber: Dokumentasi Penulis
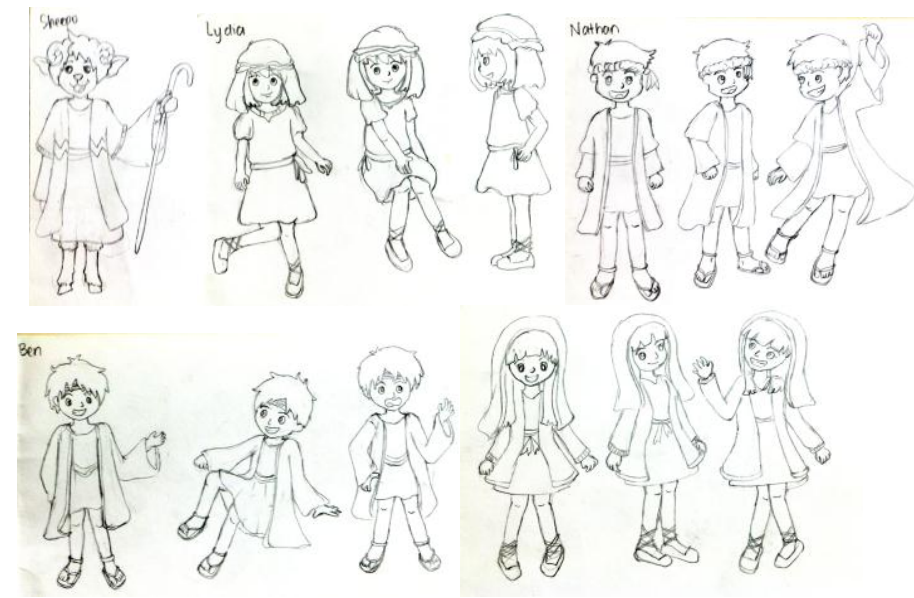

Gambar 2. Sketsa Karater The Sheepo Adventure

Sumber: Dokumentasi Penulis 

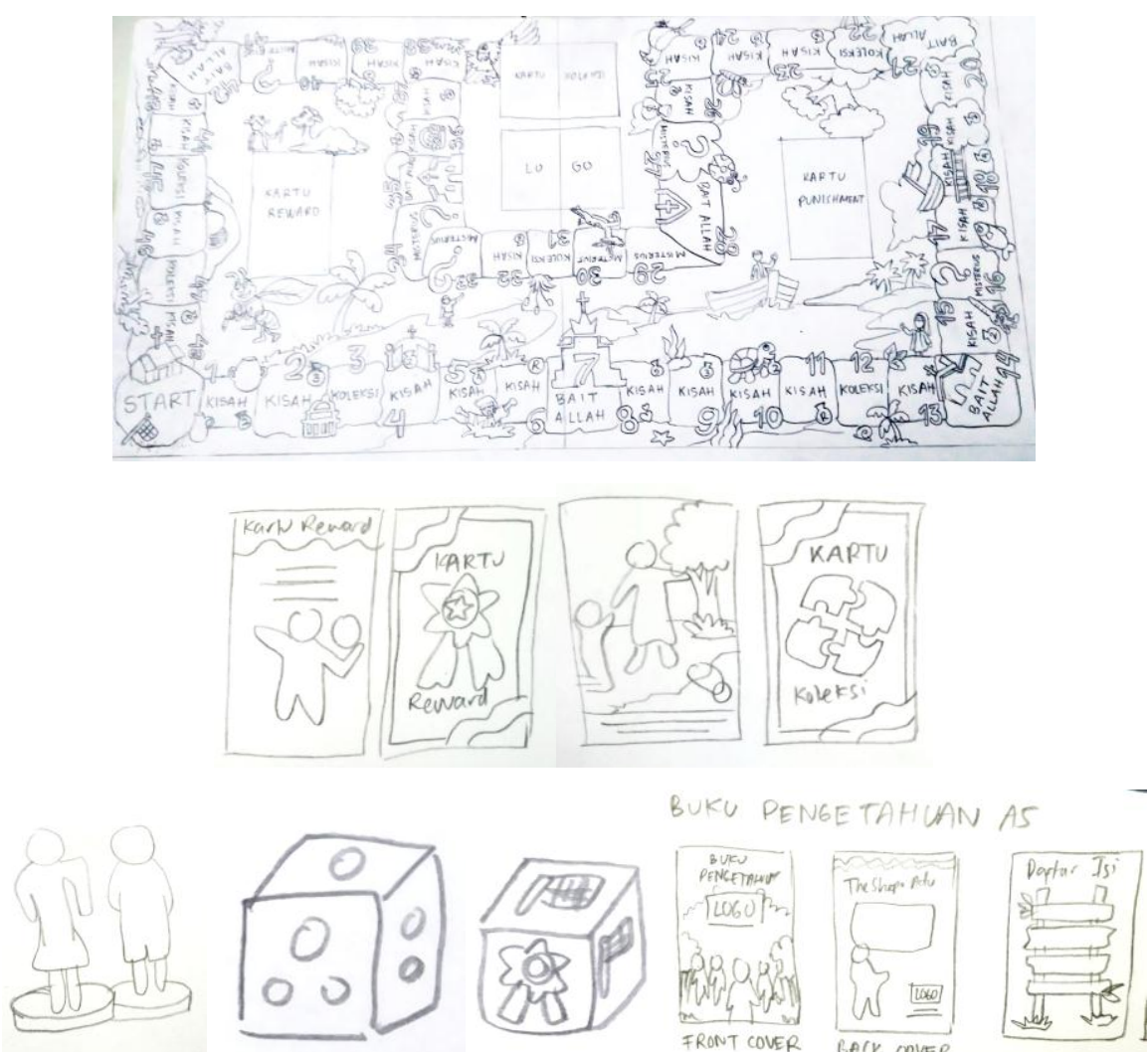

\section{Gambar 3. Sketsa Media Utama The Sheepo Adventure}

Sumber: Dokumentasi Penulis

Pemilihan nama The Sheepo Adventure berawal dari kata "Shipoo" dari bahasa Korea yang artinya bertanggung jawab dan tingkat kepedulian sosial yang tinggi terhadap orang lain, mau berkorban dan menghargai orang lain. Diambil juga dari kata "Sheep" yang artinya domba. Penggunaan binatang domba sebagai karakter utama karena domba memiliki sifat lembut, jinak dan penuh kasih sayang.

Pada proses digital alternatif, hasil sketsa kemudian diproses menjadi desain digital. Pada proses ini desain banyak mengalami revisi mulai dari bentuk, warna, detil dan lainnya. Pada tahap desain terpilih, desain yang telah direvisi disempurnakan lagi dan terdapat penambahan atau pengurangan detil. Berikut adalah kumpulan desain final board game The Sheepo Adventure antara lain: 


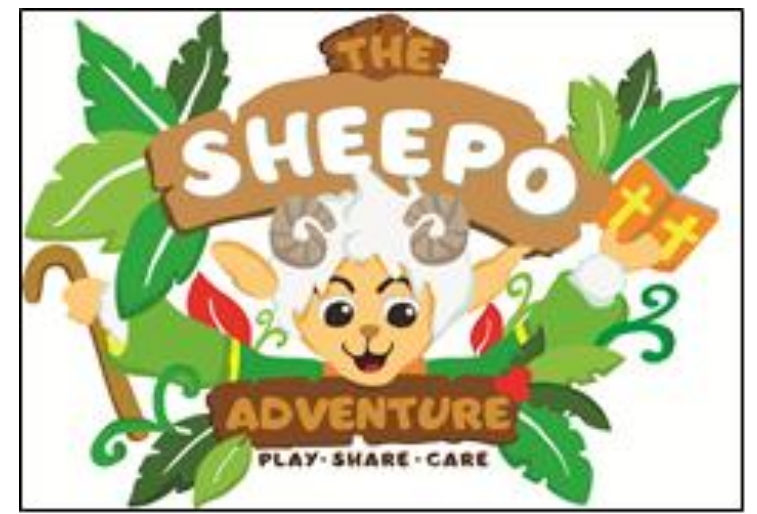

Gambar 4. Desain Final Logo The Sheepo Adventure

Sumber: Dokumentasi Penulis

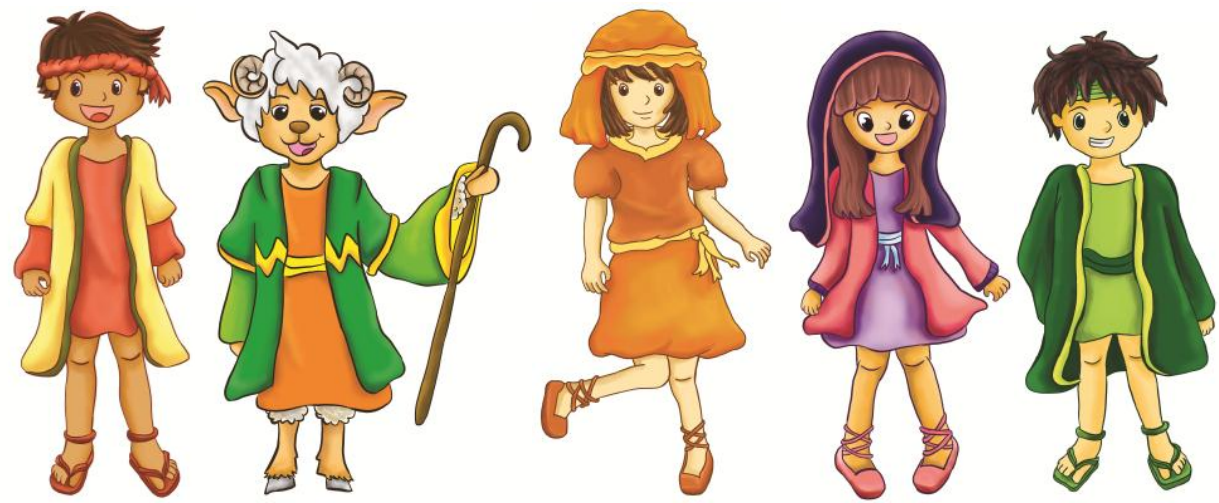

Gambar 5. Desain Final Karaker

Sumber: Dokumentasi Penulis

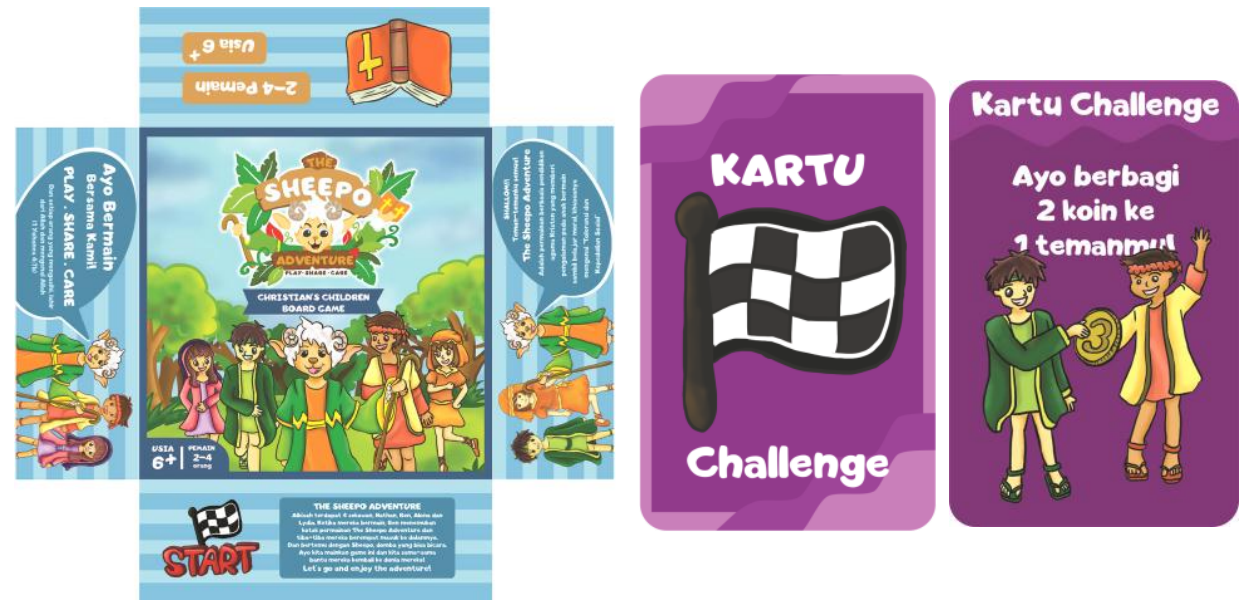



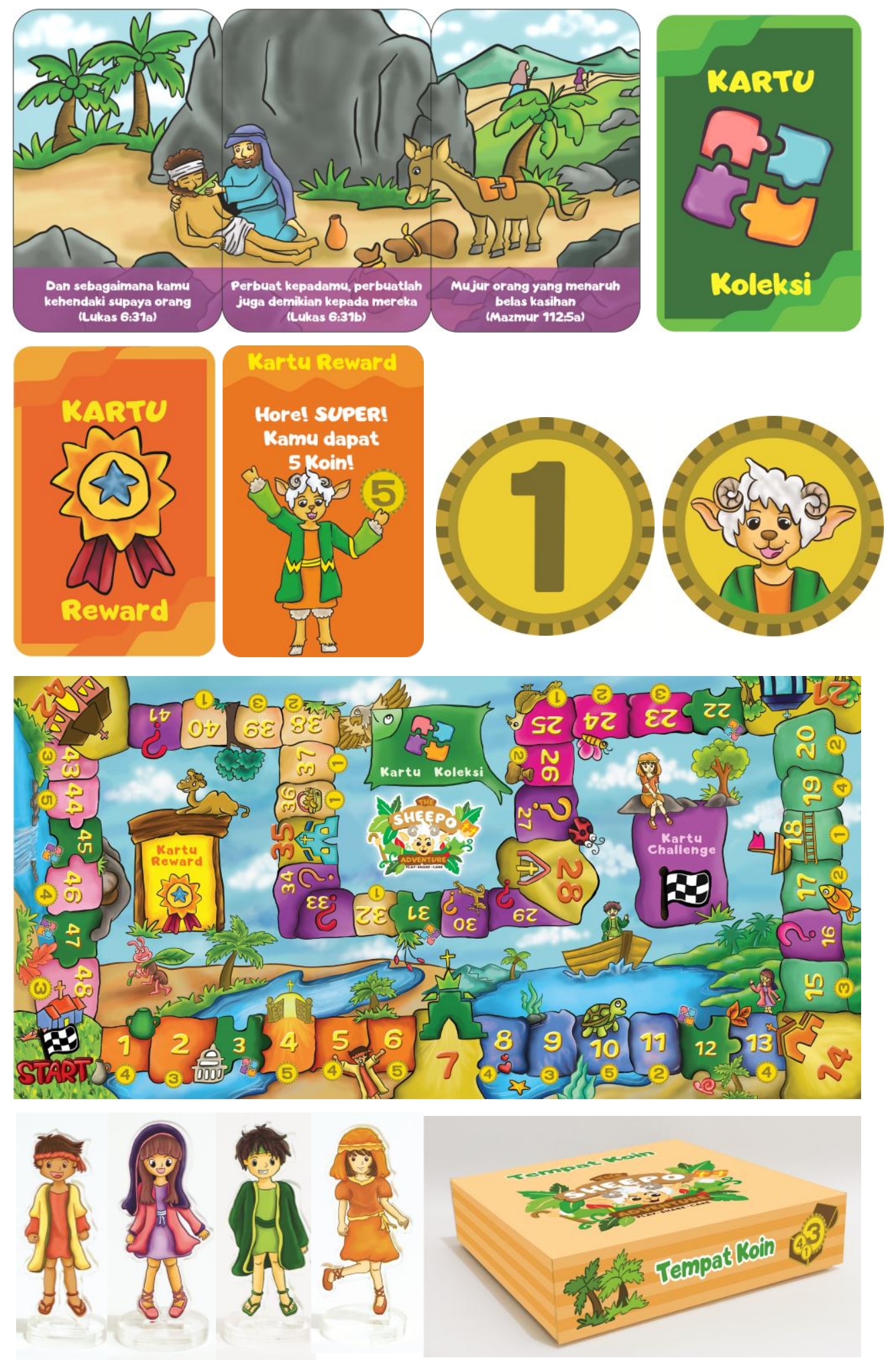

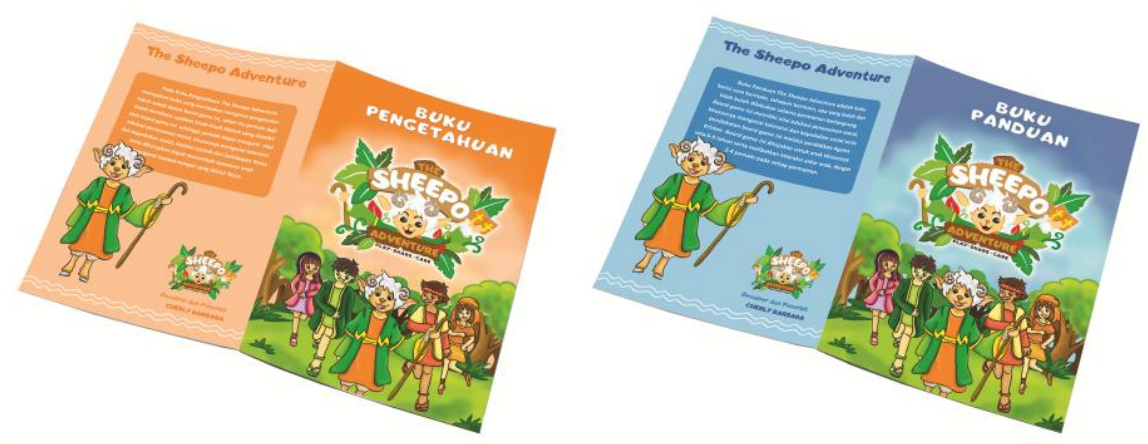

Gambar 6. Desain Final Media Utama The Sheepo Adventure

Sumber: Dokumentasi Penulisan

\section{Desain Media Pendukung}

Selain media utama juga terdapat media pendukung hyang dirancang oleh penulis sebagai media promosi board game The Sheepo Adventure ini. Media pelengkap digunkan untuk mendukung jalannya acara-acara khusus sekaligus memeriahkan acara. Terdiri dari: merchandise, souvenir, banner, leaflet, poster dan flag chain. Media promosi digunakan untuk promosi kepada masyarakat luas, sehingga board game ini dapat lebih dikenal oleh masyarakat.
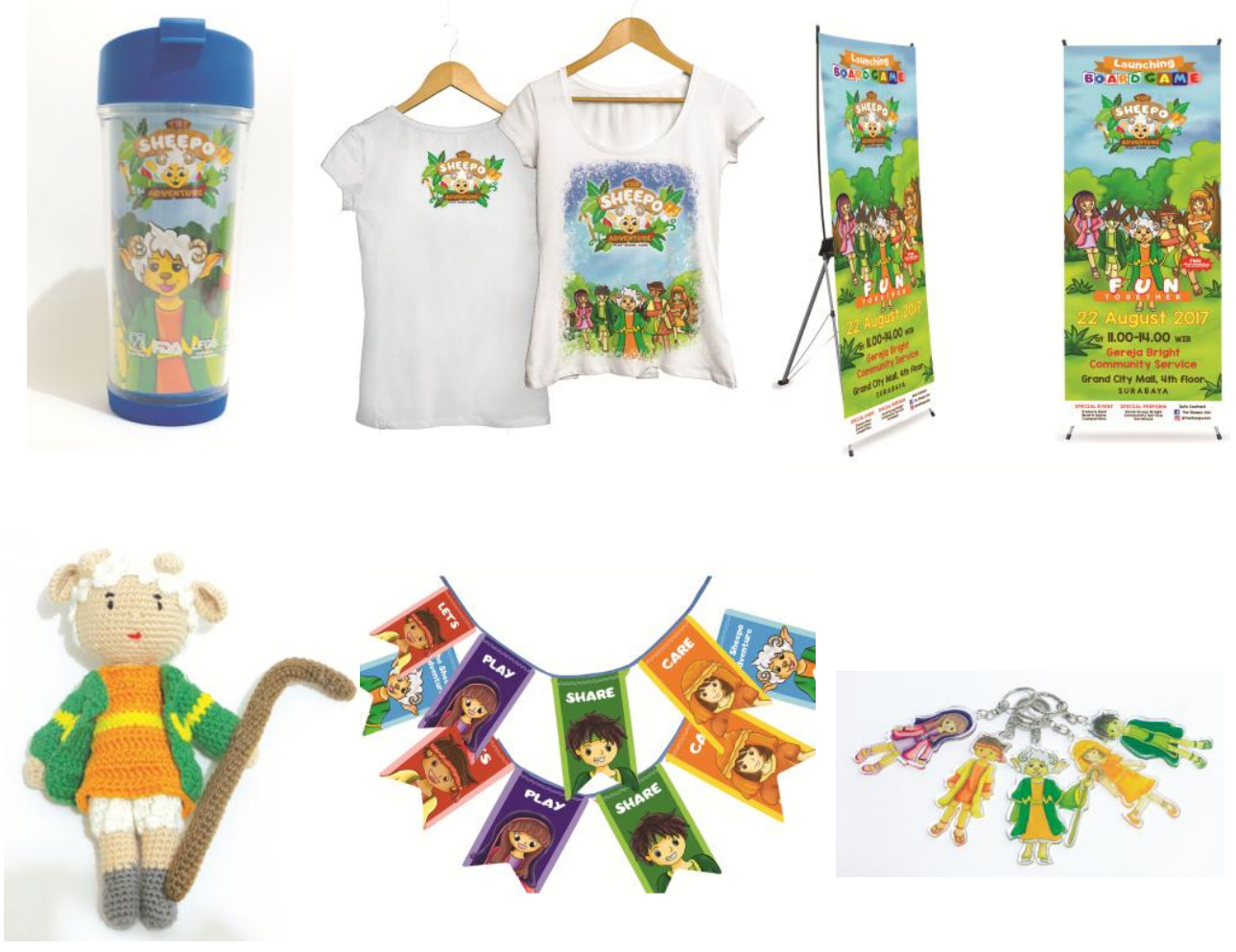

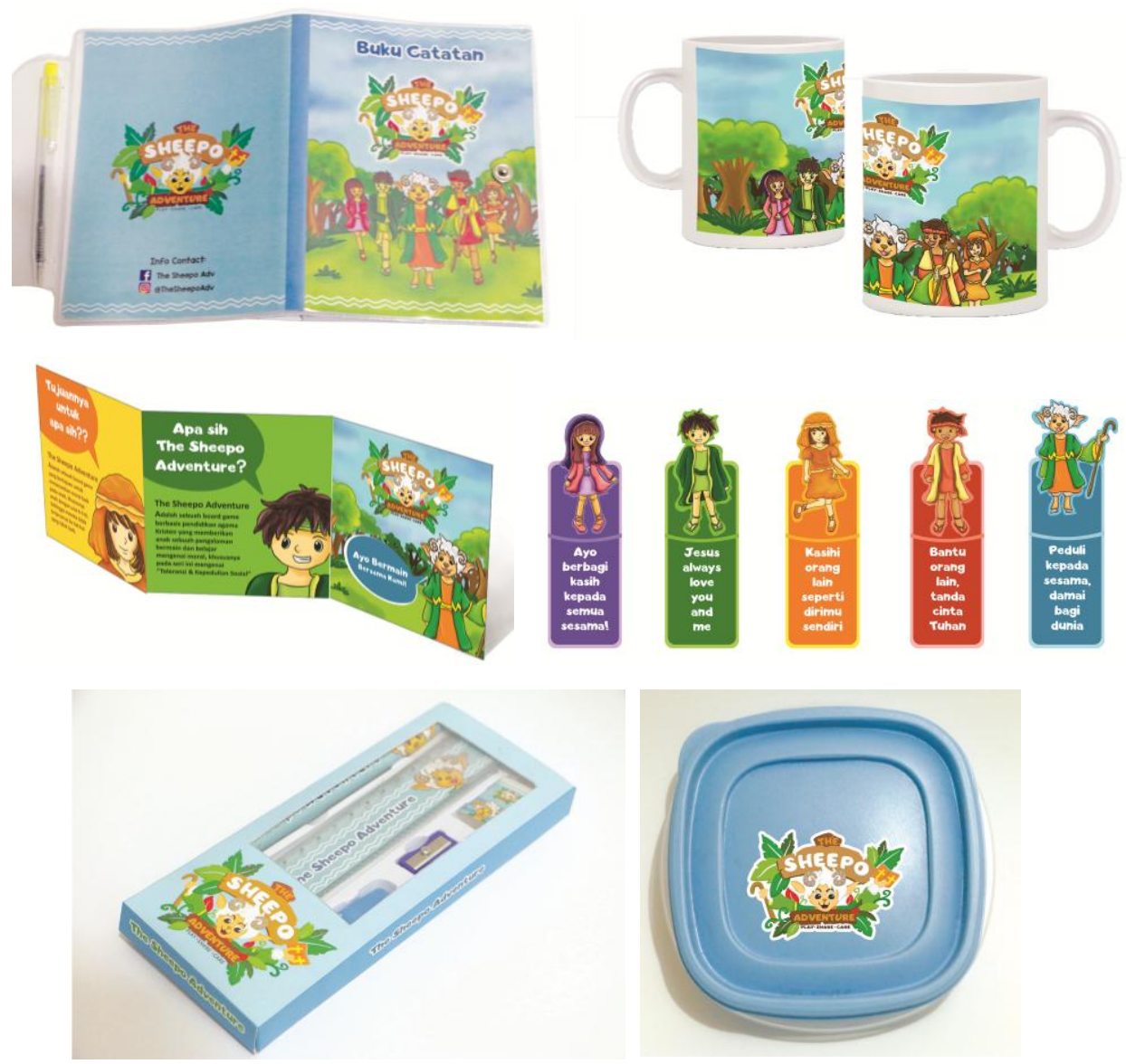

Gambar 7. Desain Media Pendukung.

Sumber: Dokumentasi Penulis

Selain itu, penulis juga melakukan tes prototype dan melakukan perbaikanperbaikan baik dari segi desain maupun teknik. Dan membuat produk board game final menggunakan bahan-bahan yang aman untuk anak-anak serta sesuai dengan target market.

\section{SIMPULAN DAN SARAN}

\section{Simpulan}

Setelah melewati proses Perancangan board game sebagai media penanaman moral bagi anak usia 6-9 tahun melalui pendekatan pendidikan agama Kristen, penulis dapat menarik kesimpulan sebagai berikut: Di dalam merancang sebuah 
papan permainan, dibutuhkan banyak ide yang didapatkan dari komunitaskomunitas board game, internet, buku, dan lainya. Menentukan konsep yang sesuai dengan kebutuhan anak, kemudian membutuhkan ketekunan, kedisplinan, ketelitian, serta kerja keras untuk dapat menghasilkan sebuah permainan yang baik untuk menanamkan moral pada anak.

Kemudian di dalam perancangan tersebut juga harus memikirkan ciri khas atau karakteristik yang menonjol dari board game tersebut, sehingga dapat diingat oleh masyarakat (brand image). Serta terdapat kendalan dalan proses perancangan seperti dalam pemilihan karakter dan warna yang disukai anak-anak. Sehingga penulis perlu melakukan voting kepada anak-anak untuk memilih logo yang mereka sukai. Pada proses pengerjaan diperlukan tenaga, dana, waktu serta percobaan, seperti mencoba mencetak kartu (bolak-balik) dalam beberapa kali, untuk dapat menghasilkan kartu dengan presisi dan baik.

Media utama yang penulis rancang pada perancangan ini terdiri dari papan permainan, pion/bidak, buku panduan, buku pengetahuan, koin, tempat koin, kartu challenge, kartu reward, kartu koleksi, tempat kartu dan kemasan. Meskipun semua media utama tersebut berbeda-beda fungsi, namun antara satu desain dengan yang lain harus memiliki keterikatan (konsisten desain), sehingga lebih mudah dikenali dan menjadi ciri khas.

Selain itu, penulis juga merancang media pendukung sebagai sarana promosi dan mengenalkan produk board game The Sheepo Adventure ini. Sama dengan media utama, media pendukung juga memiliki keterikatan satu sama lainnya dengan menggunakan warna-warna khas The Sheepo Adventure serta komunikatif dan dapat menarik minat pembeli.

\section{Saran}

Setelah melewati proses perancangan board game The Sheepo Adventure ini, penulis dapat memberikan saran bagi mahasiswa lainnya yang akan melakukan perancangan board game, sebagai berikut: 1) Di dalam melakukan perancangan konsep board game dibutuhkan ide-ide dan melakukan penelitian terlebih dahulu dalam jangka waktu yang lebih lama (disarankan untuk memainkan banyak board game). Sehingga dapat menghasilkan konsep permainan yang menarik dan sesuai 
dengan target market yang dituju; 2) Di dalam proses perancangan desain board game, dibutuhkan pengetahuan yang mendalam mengenai objek maupun subjek yang akan dirancang, teori-teori mendasar mengenai desain komunikasi visual, khususnya yang berkaitan dengan karakteristik anak; 3) Di dalam penyelesaian perancangan, dibutuhkan percobaan atau play test akhir pada target market yang dituju, sehingga benar-benar memberikan hasil yang maksimal: 4) Untuk desainer lain yang ingin merancang sebuah board game, diperlukan konsep permainan yang baik dan menarik, serta perancangan yang matang disertai dengan pengetahuan yang baik mengenai kebutuhan target market, desain komunikasi visual serta konsep board game. Melakukan survei mendalam mengenai tempat-tempat percetakan yang memiliki hasil yang baik dan harga yang terjangkau.

\section{DAFTAR PUSTAKA}

Wijanarko, Jarot.2017. Father and Son- Intim Orangtua Anak. Jakarta: Keluarga Indonesia Bahagia.

Tedjasaputra, Mayke S. 2001. Bermain, Mainan dan Permainan. Jakarta: Grasindo. Ismail Andang. 2009. Education Games. Yogyakarta: Pro U Media.

Mulyadi, S., 2004. Bermain dan Kreativitas (Upaya Mengembangkan Kreativitas Anak Melalui Kegiatan Bermain). Papas Sinar Sinanti: Jakarta. 